\title{
Retraction Note to: Candidate gene prioritization
}

\author{
Ali Masoudi-Nejad ${ }^{1}$ Alireza Meshkin ${ }^{1} \cdot$ Behzad Haji-Eghrari $^{1}$. \\ Gholamreza Bidkhori ${ }^{1}$
}

Published online: 14 September 2015

(C) Springer-Verlag Berlin Heidelberg 2015

\section{Retraction to: Mol Genet Genomics (2012) \\ 287:679-698 \\ DOI 10.1007/s00438-012-0710-z}

This article has been retracted by the Editor-in-Chief as it contains previously published figures and tables that have been re-produced without permissions from the original authors and publishers. Moreover, the article contains significant portions of other authors' writings on the same topic in other publications, without sufficient attribution to these earlier works being given. The principal author of the paper has acknowledged that contents from various publications and online sources were used in this review without permission and/or proper reference to the original sources.

The authors apologize for their negligence.

The online version of the original article can be found under doi:10.1007/s00438-012-0710-z.

Ali Masoudi-Nejad

amasoudin@ibb.ut.ac.ir

http://LBB.ut.ac.ir

1 Laboratory of Systems Biology and Bioinformatics (LBB),

Institute of Biochemistry and Biophysics,

University of Tehran, Tehran, Iran 